\title{
JUVENTUD Y BICENTENARIO Estudiantes secundarios, procesos de construcción de identidad ciudadana y discursos marginales. La Serena-Coquimbo, 2006-2009
}

\author{
ABNER ADAROS MUNCADA* \\ RUBÉN MANZANO JAURE \\ SAÚl MELLA ALARCÓN \\ DANIELA MONTERO SAAVEDRA
}

\begin{abstract}
RESUMEN
La presente proposición es atingente al momento en que vivimos como sociedad. A pasos abrumadores se aproximan las denominadas «fiestas del bicentenario» con días feriados adicionales incluidos. En este sentido, el presente artículo, desde una lógica historiográfica, quiere presentar las conclusiones de un estudio cuantitativo, llevado a cabo el año 2009 en las ciudades de Coquimbo y La Serena, con estudiantes que se aprestaban a terminar la enseñanza media. Asumiendo una postura evaluativa, semejante a la eclosionada en el Chile de 1910, cuando preclaros hombres como Enrique Mc Iver y Luis Emilio Recabarren, entre otros, discutieron acerca del Centenario de la República, se les entregó la palabra a los estudiantes de cuarto medio, próximos a terminar la enseñanza secundaria. A partir de este piso, se profundizó en temáticas como la identidad juvenil, el impacto del discurso estatal, a través de la educación formal y el peso en la «generación de opinión y pensamiento crítico/reflexivo» de la asignatura de Historia y Ciencias Sociales.
\end{abstract}

PALABRAS CLAVE: BICENTENARIO, IDENTIDAD JUVENIL, IDENTIDAD CIUDADANA, CONSTRUCCIÓN DE IDENTIDAD, SISTEMA EDUCACIONAL

* Profesores de Historia y Geografía, Universidad Pedro de Valdivia, sede La Serena. Correo electrónico: profesores.historia@gmail.com.

Resumen de tesis para optar al grado de licenciados en educación en historia y geografía, dirigida por el profesor Pedro Canales Tapia. Universidad Pedro de Valdivia, sede La Serena, marzo 2010. 


\section{JUVENTUDE E BICENTENÁRIO \\ Estudantes secundários, processos de construção de identidade cidadã e discursos marginais. La Serena-Coquimbo, 2006-2009}

\section{RESUMO}

A presente proposta diz respeito ao momento atual de nossa sociedade. Rapidamente, aproximam-se as denominadas «festas do bicentenário», que incluem feriados adicionais. Neste sentido, este artigo pretende apresentar, a partir de uma lógica historiográfica, as conclusões de um estudo quantitativo realizado em 2009 nas cidades de Coquimbo e Serena, com estudantes que cursavam a fase final do ensino médio. A partir de uma posição avaliativa semelhante àquela utilizada no Chile de 1910, quando homens ilustres como Enrique Mc Iver e Luis Emilio Recabarren, entre outros, discutiram sobre o Centenário da República, foi dada a palavra a estudantes próximos à conclusão do ensino médio. A partir desta proposta, foram aprofundadas temáticas como identidade juvenil, o impacto do discurso estatal através da educação formal e o peso na «geração de opinião e pensamento crítico/reflexi-vo» da disciplina de História e Ciências Sociais. PALAVRAS CHAVE: BICENTENÁRIO, IDENTIDADE JUVENIL, IDENTIDADE CIDADÃ,
CONSTRUÇÃO DE IDENTIDADE, SISTEMA EDUCACIONAL

YOUTH AND BICENTENARY

Secondary students, processes of the citizenship identity construction and marginal speeches. La Serena-Coquimbo, 2006-2009

\section{Abstract}

This present proposal is astringent to the moment in which we started to live as a society. At overwhelming steps the denominated «celebrations of the bicentennial» with which additional holidays have been included. In this sense, the present article, from a historical logic, presents/displays the conclusions of a quantitative study, carried out during the year 2009 in the cities of Coquimbo and La Serena, with students who prepared themselves to finish secondary education. Assuming an evaluative position, similar to the one opened in Chile in 1910, when pre-cleared men like Enrique Mc Iver and Luis Emilio Recabarren, among others, discussed the Centenary of the Republic, and submitted word students of fourth grade, near finishing their secondary education; from here on, they deepened themselves in themes such as the youth identity, the impact of the state speech, through formal education and the weight in which the «generation of opinion and reflective critical thought/» on the subject of History and Social Sciences.

KEY WORDS: BICENTENARY, YOUTH IDENTITY, CITIZEN IDENTITY, IDENTITY CONSTRUCTION, EDUCATIONAL SYSTEM 


\section{INTRODUCCIÓN}

ACTUALMENTE PAÍSES DE AMÉRICA Latina protagonizan ceremonias conmemorativas del inicio de sus procesos de independencia política de España, denominadas por las autoridades y los medios de comunicación como «fiestas bicentenario». El grito de Chuquisaca en Bolivia abrió las puertas a la conmemoración de los doscientos años de vida republicana, y Chile, en este contexto, no se encuentra ajeno a dicho hito inaugural. El debate, en este contexto, ha sido cruzado por la noción de ciudadanía y construcción de ésta.

Nuestro país desde el año 2000 en adelante inició una fuerte asonada comunicacional para instalar en la opinión pública el concepto de Bicentenario como idea de término e inicio de un capítulo en la historia de Chile. El término de la transición democrática iniciada en 1990 y el inicio de una nueva historia, más democrática y de notoria participación ciudadana. Acá también vemos cómo la discusión en torno a la construcción de ciudadanía es parte de los foros y coloquios.

Es así como los gobiernos chilenos, y puntualmente desde Ricardo Lagos en adelante, han vinculado el Bicentenario a la materialización de grandes obras públicas para conmemorar esta fecha. En este mismo sentido, los medios de comunicación han hecho su labor difundiendo megaproducciones televisivas, en donde se exacerba el ímpetu de los héroes patrios; en este caso la red de televisión de la Pontificia Universidad Católica de Chile ha encabezado esta iniciativa, reproduciendo y difundiendo interpretaciones decimonónicas que transmiten, de manera fílmica, discursos fundacionales elitistas, además de reality shows como «1810» y «1910» que farandulizan los ímpetus de conmemoración y han dejado en la retina impresiones como «conflicto», «clasismo», «discriminación» y "patriotismo».

A nivel local, podemos indicar que el Bicentenario en la ciudad de Coquimbo se materializa en una obra vial de magnitud: el bypass de La Cantera recientemente inaugurado por las autoridades, además de otras obras de infraestructura como hermoseamientos y mejoras en espacios ciudadanos. En este sentido, no se han visibilizado temas como huelgas, abusos laborales en el sector de Tambillos, conflictos poblacionales relacionados con el derecho a la vivienda y el derecho al acceso al agua y por último el conflicto de los pescadores artesanales debido los problemas que les ha acarreado la pesca por arrastre.

A nivel estudiantil podemos indicar, tentativamente, que el $\mathrm{Bi}$ centenario entre los jóvenes —-según sus palabras- no tiene un im- 
pacto mayor, pues no existe una propuesta de sentido que explique entre ellos la importancia de dicha conmemoración. Es más, desde el Mineduc, los planes y programas relacionados con la temática son ínfimos y en ocasiones inexistentes de acuerdo a una revisión de los textos escolares respectivos. Resulta interesante destacar que la unidad referida al proceso de Independencia no presente mayores indicaciones que promuevan este hito histórico. La unidad aludida (la creación de una nación) presenta de manera superficial y con poca proyección al presente, la temática histórica, y solo se remite a la Independencia de Chile como acontecimiento histórico sin importancia para el hoy; por lo tanto sin proyección histórica hacia el Bicentenario o la formación ciudadana de los jóvenes que cursan cuarto medio.

Este último punto es relevante. La sociedad chilena espera que las generaciones egresadas de cuarto medio sean capaces de asumir el rol de ciudadano participativo políticamente, comprometidos con el quehacer social, conocedores de sus derechos y deberes cívicos y respetuosos del medio ambiente.

El enfoque de estudio, entonces, se refiere al estudio de la identidad ciudadana en jóvenes próximos a egresar de enseñanza media. En este sentido cabe preguntar: ¿fomenta la conmemoración del Bicentenario la construcción de identidad ciudadana entre los estudiantes? ¿Qué esfuerzos despliega el Mineduc por impactar favorablemente en la formación ciudadana de los estudiantes? Dicho de otra manera, ¿de qué forma construyen en el día a día su ser ciudadano los estudiantes de cuarto medio? Por último, ¿de qué manera se expresa esta identidad en los jóvenes estudiantes?

A puertas de conmemorar el segundo centenario de la República de Chile creemos que es relevante dar énfasis en el proceso de construcción de identidad ciudadana en la juventud chilena. Esto debido a que toda construcción social moderna en los marcos democráticos actuales necesita fortalecer la construcción de ciudadanía, en gran medida por la propuesta de participación y compromiso de los actores intervinientes en dicho proceso.

En este sentido, el Ministerio de Educación ha tenido la oportunidad en los últimos años de trabajar junto a los estudiantes de enseñanza media el impacto de esta conmemoración y su materialización en el mundo juvenil. Como contribución, entonces, de nuestro trabajo proponemos visualizar los mecanismos de construcción de identidad ciudadana en los estudiantes de cuarto año de enseñanza media, toda vez que este segmento de jóvenes se localizan en el umbral de la vida 
adulta, elaborando un documento que permita debatir y reflexionar a las autoridades competentes en torno al diseño y énfasis de los planes y programas del subsector de Historia y Ciencias Sociales.

Debemos consignar antes de pasar al siguiente punto que los comentarios, reflexiones y datos expuestos en estas líneas nacieron de una investigación de corte cuantitativa, a partir de encuestas de opinión y un claro propósito de participar en el debate hacer del Bicentenario. Con el fin de socializar las conclusiones de forma atractiva y contributiva, hemos excluido de este documento gráficos, curvas y archivos de datos.

\section{BREVE DISCUSIÓN TEÓRICA}

A partir de las siguientes preguntas ¿qué se entiende por identidad ciudadana?, ¿cómo se construye la identidad ciudadana en los jóvenes? y ¿a través de qué procesos? iniciaremos la presentación del marco teórico que sustenta nuestra investigación, la cual está desarrollada desde una lógica de lo general a lo particular, en este caso desde una discusión iniciada a nivel latinoamericano para decantar en la coyuntura chilena.

Desde principios de la década de 1990, surge fuertemente el protagonismo juvenil en América Latina, esta vez ya no bajo el alero de esperanzas ni de cambios sociales, sino que ahora bajo el estigma generalizador de la «leyenda negra». Si bien en América Latina se avanzó significativamente en los procesos democratizadores, al mismo tiempo muchos jóvenes han pagado los costos políticos de los últimos años.

Las interpretaciones tradicionalistas visualizan la identidad como un proceso histórico en el cual existiría una especie de sustancia casi genética en las naciones o pueblos, y que ésta sería inmutable a los procesos de transformación y construcción social. Por esta razón existe un malestar en los que sustenta esta teoría, debido a la constante «crisis de identidad» a la cual se refieren.

Dentro de esta perspectiva analítica, este trabajo propone plantear que las identidades están en constante construcción y transformación, que no poseen una variante sustancial que sea fundamental en el proceso identitario. Un ejemplo, es el caso de las juventudes actuales, que poseen matices totalmente heterogéneos y complejos, en los cuales poseen más rasgos de acercamientos con culturas extranjeras, influidos por los medios de comunicación, o a veces por microidentidades 
construidas en base a los cimientos de los contextos territoriales; es así como «el aporte fundamental de la discusión sobre identidad en las últimas décadas apunta a la desustancialización del concepto, por una parte, desde el campo de su historicidad y por otra desde la teoría cultural» (Rozas y Arredondo, 2006).

Los medios de comunicación, los actuales contextos globalizadores, las nuevas formas de relacionarnos socialmente, han calado hondo en la sociedad y las juventudes:

...hay huellas de las grandes transformaciones culturales ocurridas en las últimas décadas. Nos referimos entre otras a la más mediatización y organización audiovisual de la cultura, que afecta a todas las actividades: desde la política hasta la educación, desde el teatro y la literatura hasta la religión; desde el amor hasta el miedo. Nos referimos también a las innovaciones tecnológicas, a la estética del zapping, a la TV y la internet, al teléfono celular y a lo multimedial (Rozas y Arredondo, 2006:20).

La identidad se construye dependiendo de los contextos en los cuales las sociedades se sitúan. En el caso de las juventudes y las identidades ciudadanas es necesario replantarse los planteamientos decimonónicos al respecto de manera urgente para poder comprender, desde la discusión actual, los contextos en los cuales las juventudes ejercen su ciudadanía.

De acuerdo con el párrafo anterior, podemos consignar que con la instauración del modelo neoliberal de crecimiento y el repliegue de los Estados benefactores, comienzan a construirse nuevos escenarios sociales y económicos; en este mismo sentido, emerge como prioridad de los gobiernos dar preferencia al desarrollo económico sin regulación, favorable a la dinámica de mercado y claramente excluyente de gran parte de la sociedad en la incorporación productiva al sistema, lo cual ha provocado en los jóvenes desconfianza y rechazo hacia el Estado, las políticas públicas, y la institucionalidad vigente en general. ${ }^{1}$

En este sentido, las formas de construcción social, económica y políticas han cambiado aceleradamente en los últimos treinta años. En estos nuevos contextos los jóvenes son parte de un proceso de globali-

1 Ver autores tales como Alain Touraine en Francia y Manuel Antonio Garretón en Chile, los cuales postulan que con el cambio de estructura estatal también cambiaron las estructuras de participación social, surgiendo nuevos actores sociales relevantes, entre ellos, los estudiantes secundarios. 
zación, que los hace constituirse como sujetos sociales complejo de ser definidos y categorizados, en gran medida por el influjo de la tecnología, el Internet, los medios de comunicación, el individualismo, los efectos del «tiempo real» y la noción de cambio perpetuo.

Claro está —en este contexto- que las juventudes son heterogéneas, complejas y portadoras de proyectos diferenciables, según los últimos estudios sociales, encabezados por prestigiosos académicos como Alain Touraine, Lydia Alpizar, Marina Bernal, Rossana Reguillo, Juan José Cañas, entre otros; al parecer se ha hecho compleja la incorporación de nuevas interpretaciones académicas al quehacer político-social.

Ser ciudadano y ejercer la ciudadanía es sin duda una de las instancias más significativas en los procesos de participación política dentro del quehacer social. Para Rossana Reguillo, existen tres modelos de ciudadanía que han venido rigiendo en la historia contemporánea de siglo XX.

A nivel juvenil, evidentemente existe una gran contradicción, por un lado se ve a los jóvenes no aptos para participar de los procesos ciudadanos (menores de edad), pero por otro son aptos para convertirse en sujetos de castigos (ley penal de responsabilidad juvenil). En este mismo sentido, la ciudadanía ha adquirido nuevas interpretaciones por parte de la clase política, la cual ve a los ciudadanos como «clientelas electorales» y los que no votan son vistos como piezas incómodas para la organización social.

Así es como el Estado y los gobiernos de los últimos veinte años en América Latina entienden a los jóvenes como sujetos de políticas públicas, de proyectos, de programas, pero no como interlocutores calificados en temas políticos. A esto se suma el hecho de que «en nuestras sociedades la idea de una ciudadanía tutelada por el Estado para el caso de los jóvenes menores; es decir, cuando es el propio Estado el que responde ante la sociedad por estos jóvenes», idea altamente valorada por la sociedad.

En sus postulados, historiadores, sociólogos e investigadores de la temática social han puesto un fuerte énfasis en la urgente tarea de reformular el concepto de ciudadanía, pues éste en la práctica posee notorias características de clasismo, sectarismo y marginalidad. Es así como se postula la necesidad de ver a la ciudadanía no como «un concepto restringido a la formalidad de su definición, es necesario pasar a una concepción abierta capaz de recoger la multidimensionalidad y complejidad de los procesos de pertenencia en las sociedades contem- 
poráneas, especialmente las latinoamericanas» (Reguillo, 2003:19). Pues ser ciudadano, «más allá de sus definiciones formales, consiste en el acceso a un conjunto de garantías sociales cuyo sentido es el de ofrecer una plataforma mínima de seguridad que busca equilibrar los desniveles sociales (Reguillo, 2003:19).

El ser ciudadano va más allá de la formalidad. En este sentido, Paola Dinamarca, psicóloga especialista en temáticas juveniles, plantea que «hay que ser bastante cuidadoso en el tema de la ciudadanía, porque, ¿quién te da la categoría de ser ciudadano? Por ejemplo, desde la convención de los derechos del niño, el solo hecho de nacer en un país da tal categoría de ciudadano». En esta lógica, la psicóloga plantea que «la ciudadanía es un atributo que te da el Estado, automáticamente te da un estatus de carácter jurídico y eso tiene varias implicancias en la vida de las personas, porque uno como ciudadano tiene derecho a expresar sus ideas políticas, sus preferencias civiles, sus preferencias de carácter social, y que les permiten a las personas intervenir en el quehacer público, tener derecho de voz y voto, y poder opinar, eso es ciudadanía en la práctica, implica elegir y ser elegido, y gozar de ciertas libertades, son hartas cosas por lo tanto» (Dinamarca, entrevista).

Evidentemente, el carácter de ciudadanía posee una complejidad en sí misma, pero se focaliza en el hecho de que el ciudadano debe tomar un rol activo en el quehacer público, lo que en la práctica de las políticas de América Latina no han logrado materializarse. Es así y siguiendo el postulado de la psicóloga Dinamarca y refiriéndose al carácter del ser ciudadano «en Chile y en general en América Latina, el mundo joven siempre se asocia con problemáticas como embarazos, drogas, y las políticas públicas van dirigidas a los problemas, todo tiempo pasado fue mejor, con una mirada adultocéntrica, pero por otro lado se ve a los jóvenes como promesa de futuro, es una mirada compleja» (Dinamarca, entrevista).

Por otro lado, es evidente que existe un vacío en la institucionalidad política juvenil, en donde cada vez más los jóvenes se ven decepcionados y desinteresados por la política y la ciudadanía formalizada. En esta misma lógica, y específicamente jóvenes «de liceos municipales de la comuna de Puente Alto, entrevistados en una investigación realizada por Gangas en el año 2005, señalan que no se sienten identificados con el sistema político ya que éste no responde a sus intereses, mientras que el $71 \%$ señala que los partidos sólo se acuerdan de los jóvenes en las campañas electorales» (Gangas, 2005:40). 
No todos los jóvenes, según el Programa de Naciones Unidas para el Desarrollo (PNUD), tienen acceso a la cultura; independiente de sus intereses y motivaciones, esto determina la construcción de identidades individuales o colectivas. Lo que dificulta el acceso a la cultura en los jóvenes son, el nivel socioeconómico, edad, tener hijos, la ubicación geográfica. En Santiago están los jóvenes de mayor índice de consumo cultural, que tienen un nivel socioeconómico medioalto, menores de 26 años y sin hijos. En definitiva, existen intereses comunes pero no recursos compartidos que influyen en definir y realizar sus proyectos de vida.

Según el PNUD, los jóvenes son quienes más apoyan la diversidad social, ellos son hijos de una sociedad que valora el libre mercado y los ideales democráticos, los jóvenes proponen que la pluralidad debe fomentarse primero. Mientras más jóvenes los entrevistados, tanto más aprecian la diversidad de intereses como algo positivo para el desarrollo del país. Mientras más edad tienen, más relevancia le atribuyen a los intereses comunes (PNUD, 2002). El segundo indicio proviene de las relaciones sociales, mientras más jóvenes son los entrevistados, más prefieren relacionarse con personas distintas que les permitan conocer experiencias novedosas (PNUD, 2002).

Según el PNUD, los jóvenes son quienes contribuyen a una mayor tolerancia y presentan una menor discriminación en relación con los adultos mayores. Lo que supone un aporte para el desarrollo humano principalmente. Debido a que la sociedad en la que estamos insertos requiere una mayor tolerancia, considerando que los modos de vida de las personas varían progresivamente, van cambiando y son diferentes, por lo que se necesita mayor tolerancia y de esta manera evitar la tendencia a la exclusión de lo diferente (PNUD, 2002).

En palabras de Touraine, «La juventud no es una categoría social, sino una construcción cultural y administrativa, una parte de la imagen que una sociedad tiene de sí misma» (Touraine, 1996:1). Para este grupo existen dos miradas u oposiciones que tiene Chile hacia la juventud: una relacionada con jóvenes de clase media y la otra con jóvenes marginales. Sin embargo, tiene otro sentido profundo, según este autor: la oposición entre dos imágenes que tiene la sociedad de sí misma y de su porvenir.

Para Touraine, «una política de la juventud parece tener que manifestarse forzosamente a través de instituciones y gestos públicos» (Touraine, 1996:1). Según este autor, en Chile se han creado centros juveniles o centros socioculturales que tienen doble objetivo: fomentar 
las actividades colectivas e impedir que los jóvenes aislados busquen una distracción en la delincuencia, alcoholismo o en la droga. Sin embargo, en ocasiones los jóvenes se sienten sometidos a la vigilancia o víctimas de un paternalismo, lo cual los irrita o los asfixia creando una contracultura frente a los centros juveniles y desperdiciando la ayuda entregada, por eso hay [...] que impedir que los jóvenes más desamparados entren inexorablemente en el círculo vicioso de la marginalidad, que convierte la falta de trabajo o de educación, o la desorganización de la familia, en incapacidad de llevar a cabo un esfuerzo personal o en encierro en una banda más o menos delincuente (Touraine, 1996:4).

Siguiendo esta discusión, Juan José Cañas sostiene que «el lugar de la juventud, y en especial la que se encuentra en situaciones de pobreza, una gran mayoría, está justamente allí, frente a los paradigmas, las incertidumbres y los retos de insertarse o marginarse, de incorporarse o rechazar estas realidades» (Cañas, 2003:5). Así mismo, «nos referimos a jóvenes incorporados o que tratan de incorporarse a dinámicas organizativas de diversa índole, que pertenecen al grueso de la población de la ciudad, de estratos socioeconómicos bajos y medios-bajos, que intentan, a través de proponerse unos proyectos colectivos, incorporarse a una sociedad paradójica: que, por un lado, los rechaza desde sus dinámicas económicas, políticas, educativas y culturales, y por el otro, los presiona para que se incorporen a las filas militares» (Cañas, 2003:5).

De acuerdo con el estado del arte, los jóvenes construyen formas de ciudadanía fuera de las normas institucionalizadas. Según investigaciones recientes, se afirma que uno de los métodos son las organizaciones de autoeducación en las cuales se desarrollan nuevas formas de enfrentar los vacíos institucionalizados.

Considerando los postulados de López, «las organizaciones de autoeducación popular hacen referencia a una heterogeneidad de colectivos fundamentalmente formados por jóvenes, pero en los que también participan (cuando el mercado laboral lo permite) mujeres y adultos. Históricamente, estas organizaciones han estado presentes en el amplio espectro del campo popular y orientan su práctica a suplir las falencias que el sistema educacional en su atención a los sectores más postergados tiene, o a proponer contenidos y formas de autoeducación alternativas a las promovidas por el sistema educativo formal, institucionalizado en la escuela pública y particular subvencionada actualmente» (López, 2006). 


\section{CONSTRUCCIÓN CIUDADANA EN EL NORTE CHICO}

Asumiendo como punto de referencia de este estudio los estudiantes de cuatro medio de Coquimbo y La Serena, generación 2009, fue considerada la historicidad de dicha generación. En 2006, la «revolución pingüina» fue centro de la noticia y la protesta, signo de un profundo malestar. En este contexto, los jóvenes analizados fueron parte constitutiva de dicho proceso. Las interrogantes a dilucidar se relacionan con los mecanismos y procesos de construcción de identidad ciudadana y la caracterización que los jóvenes hacen de dicho proceso, los espacios, mensajes y conflictos que poseen frente a esta coyuntura.

\section{a) Mecanismos y procesos en la construcción de identidad ciudadana}

Enfocándonos en el estudio de las «opiniones» e «impresiones» de los jóvenes estudiantes por el ámbito social e histórico, así como también de la noción del concepto ciudadanía que ellos poseen, articulamos la siguiente respuesta relacionada con la síntesis del objetivo número uno de la investigación, enfocada a las formas en que los estudiantes construyen los mecanismos y procesos de la construcción ciudadana.

Los mecanismos y procesos de identidad ciudadana se refieren a cómo los jóvenes crean instancias sociales para ejercer la ciudadanía, como aquí está definida. Para lograr identificar de qué manera la construyen, hemos aplicado una encuesta que arrojó interesantes y curiosos resultados que revelan la actual interpretación y visión social e histórica en que se encuentran los jóvenes de nuestro país.

¿Cuál es el grado de interés de los jóvenes estudiantes frente a su participación ciudadana y compromiso político? ¿Cómo logran un rol activo y participativo en el desarrollo de la vida en sociedad ya sea en torno a su comunidad escolar, la ciudad o pueblo en el que conviven? Son inquietudes que más adelante iremos revelando.

Resulta curioso que los estudiantes no deslegitimen el carácter de ciudadano emanado desde el Estado; pero del mismo modo no reconocen una significancia trascendental en la formación de su ciudadanía. Paradójicamente, si consideran que sus prácticas desarrolladas fuera de la institucionalidad son de igual manera formas de ejercer ciudadanía, de esta manera podemos inferir que para los jóvenes estudiantes el ejercicio de la ciudadanía posee mayor significancia fuera de lo institucionalizado que dentro de ésta. 
Resulta compleja esta paradoja, pues por un lado no reconocen fundamental significancia a la ciudadanía emanada desde el Estado, pero sí revelan un valor fundamental a la ciudadanía creada por ellos mismos, en el «cara a cara», en el aula, en la calle, en la música. Por lo tanto, estamos frente a una nueva conceptualización de la noción de ciudadano, más amplia, más diversa y más integradora. Así este fenómeno conceptual se convierte en un importante desafío para las políticas de Estado y para las ciencias sociales. Pues resulta realmente relevante que los estudiantes consideren que sus amigos sean agentes en la formación ciudadana, por sobre el Estado y la Constitución Política, comprendiendo esto podemos determinar que las formas de relacionarse socialmente los jóvenes dentro del espectro social se basa en la articulación de estos nuevos discursos conceptuales.

Así mismo, además existe un claro desconocimiento con respecto a la Constitución de la República de Chile con respecto al carácter fomentador ciudadano. Los jóvenes dan clara evidencia de un sesgo con respecto a la Constitución, demostrando de esta manera, a modo tentativo, que la educación cívica impartida por los docentes en el periodo secundario no ha logrado un resultado pleno y satisfactorio con respecto a los objetivos deseados por el plan curricular.

Resulta importante desarrollar una conclusión tentativa con respecto a por qué los estudiantes han construido estas concepciones en torno a la ciudadanía, en donde se desvalora todo lo que provenga del Estado, lo político partidista y lo institucionalizado. Lo paradójico es que se desvalora completamente, pero no se niega su relevancia, y aun así a pesar de la desvaloración, curiosamente se reconoce el carácter relevante a la hora de incentivar la ciudadanía. Sin embargo, emerge con fuerza el reconocimiento de las instancias cotidianas, entre pares, familiares, etc., como expresiones o aportes a la construcción ciudadana.

Consideramos que esta idea se desarrolla debido a la evidente deslegitimación de las juventudes desde el sector político-estatal. Producto de la poca sintonía que las decisiones políticas han tenido con los proyectos juveniles, en donde más que un interlocutor calificado, se ve a los jóvenes como programas de gobierno, en donde solo se limitan a fomentar actividades relacionadas con la salud, el deporte, programas antidrogas, de sexualidad, etcétera. Programas comúnmente diseñados y aplicados desde el Instituto Nacional de la Juventud (INJUV) u otro referente por una mayoría no jóvenes.

Con respecto a la ciudadanía, las interpretaciones decimonónicas con lineamientos positivistas planteaban que ejercer la ciudadanía era 
la capacidad de los civiles de insertarse en el sistema de elecciones políticas, de ejercer sus derechos y respetar sus deberes. Estos lineamientos teóricos están vigentes hoy en día en la constitución de los Estados latinoamericanos y chileno. Por lo tanto, planteamos que el Estado se ha construido bajo una lógica sectaria, discriminativa y autoritaria, según la interpretación juvenil; dicho de otro modo, los jóvenes ven en el Estado la noción de autoritarismo, es así como entonces se crea la interacción y la construcción identitaria y ciudadana fuera de la institucionalidad estatal, buscándose nuevas interpretaciones y modos de ejercer una ciudadanía no tradicional, pero sí más vanguardista en términos académicos actuales. Estas son formas en donde no se reconoce la institucionalidad, pero sí se reconocen la marginalización, la autonomía y el desarrollo acorde a sus necesidades y realidades. López al respecto sostiene:

La participación juvenil en el padrón electoral del país ha descendido desde el $20 \%$, pasando por el $14 \%$ hasta ocupar actualmente un $8.9 \%$ del padrón electoral según la última elección de alcaldes y concejales de los años 2004. Los partidos políticos disminuyen aceleradamente su contingente juvenil, al año 2004, el 86,3\% de los jóvenes entre 15 y 29 años afirma no identificarse con ningún partido político. El 70\% de los jóvenes entre estos mismos tramos de edad no está inscrito en los registros electorales. El 43\% de ellos es porque afirma no interesarse en la política, un $13 \%$ porque los políticos no les dan confianza y el $12 \%$ simplemente por falta de tiempo; es decir, un incremento poco significativo en caso de aprobarse un sistema de inscripción automática (López, 2006:11).

Claramente observamos que los jóvenes no se motivan en participar en política u otra actividad similar, debido a que no existen los espacios, recursos y apoyo necesarios para que esto sea posible dentro de sus intereses. Los jóvenes hoy en día son claramente marginados de movimientos u acciones tendientes a fomentar su participación ciudadana plena.

La ciudadanía para los jóvenes no es más que una participación ficticia y que no se materializa por la falta de apoyo, los jóvenes sólo encuentran respaldo a sus ideales dentro de su núcleo familiar y sus pares; según el instrumento, la mayoría de los jóvenes poseen ideales y sueños de un mundo mejor.

Resulta importante destacar el desprestigio que las sociedades latinoamericanas han depositado en los jóvenes, considerándolos problemáticos, generando así en el ideario juvenil un sentimiento de re- 
chazo y discriminación, que consideramos que es el factor principal de por qué los jóvenes se marginan del sector oficializado, para depositar sus ideales y sueños en la creación de discursos no oficializados. En esta lógica, a propósito del ideal creado por los jóvenes, la pregunta con respecto a que si carabineros respetaba los ideales juveniles, la respuesta de los jóvenes permite que se establezca la poca sintonía con la oficialidad política y social, que plantea este trabajo.

Evidencia de este planteamiento es el rol que los estudiantes dan a la familia con respecto a sus ideales sociales y ciudadanos, a diferencia de cómo ven al Estado. Podemos inferir que si bien la base fundamental de la sociedad chilena está aparentemente en una crisis de legitimidad, como tanto se ha repetido, por otro lado también es un baluarte por parte de los estudiantes en el tema del respeto de sus ideales y el valor con respecto al fomento ciudadano.

En relación a los establecimientos educacionales y los profesores, los resultados demuestran una interesante conclusión respecto a la percepción que los alumnos tienen en relación a la escuela y los docentes en su formación como ciudadanos participativos.

Uno de los mecanismos más relevantes a considerar es la noción que tienen los estudiantes con respecto a los profesores y los establecimientos. En este sentido los alumnos le entregan un importante valor al trabajo docente, pero paradójicamente la escuela pierde relevancia para los estudiantes en relación al fomento y el aporte ciudadano.

La ciudadanía es un objetivo del aprendizaje escolar y es vital mejorar la formación en este ámbito para fortalecer la cohesión de nuestra sociedad, erradicar problemáticas de convivencia social y mejorar la calidad de vida de la población. Para esto es necesario que la escuela no excluya los contenidos que el propio mundo juvenil propone, son estos los que mayor sentido le otorgan los jóvenes, los que apuntan a un horizonte utópico, a una transformación en el desgastado campo de la política formal (López, 2006:29).

\section{b) Construcción y caracterización de las expresiones de identidad ciudadana}

A partir de los resultados obtenidos en base a los instrumentos aplicados en los establecimientos educacionales, presentaremos las interpretaciones. Éstas tienen como objetivo demostrar las formas en que los estudiantes caracterizan la expresión de identidad ciudadana; dicho de otra manera, cómo éstos expresan su identidad ciudadana. 
Volviendo a la estructura del marco teórico — donde el concepto y la lógica ciudadana han sido abordados desde una perspectiva histórica y donde el término ha recibido múltiples interpretaciones y construcciones-, debemos destacar que en lo medular la ciudadanía «más allá de sus definiciones formales, consiste en el acceso a un conjunto de garantías sociales cuyo sentido es el de ofrecer una plataforma mínima de seguridad que busca equilibrar los desniveles sociales» (Reguillo, 2003:7). En este mismo sentido, pero visto desde otro autor, «el ejercicio en sí de la ciudadanía significa participar en asuntos de carácter público» (Dinamarca, entrevista).

Mauricio Hoyos, por su parte, postula que la ciudadanía radica en vivir en un contexto físico y social que respete y dialogue con la diferencia, en un ambiente con igualdad de oportunidades y posibilidades de acceso a condiciones de vida digna y estar incluido en un tejido social donde se reconozca y permita la capacidad de cada cual de incidir en las decisiones que lo afectan, con capacidad de forzar la legalidad a favor del bien común.

Es así cómo las nuevas formas de concebir la ciudadanía se construyen paralelamente en cómo la ciudadanía misma, y en este caso los jóvenes, conciben el ser ciudadano, el construir nuevas formas de ejercer la ciudadanía, y esto se ve graficado en el estudio mismo en cuestión. Veamos.

$\mathrm{Al}$ aplicar las encuestas, y analizar los posteriores resultados, se consiguieron datos muy interesantes, que se pueden relacionar paralelamente con la estructura teórica de este estudio.

Al preguntar a los estudiantes si los políticos regionales representaban sus ideales ciudadanos, el 86,2\% se inclinó por la opción no, a diferencia de un apenas 13,2\% que cree que sí son representados. El rechazo a la política partidista y a las instancias institucionales es producto de la poca sintonía que los políticos poseen con las identidades juveniles ciudadanas, lo que no quiere decir que los jóvenes no estén ejerciendo una ciudadanía o interesados en asuntos de carácter público.

Dinamarca sostiene al respecto que «lo que pasó con la revolución pingüina en mayo del 2006, fue la gran sorpresa que dieron los jóvenes al Estado y a nosotros como país, porque jamás pensamos que estos niños tenían capacidad de visualizar, capacidad de ver más allá de lo que le entregan, de voto y de poder criticar, cuando generalmente se decía que los jóvenes no estaban ni ahí con nada, pero lo que pasa es que no estaban ni ahí con las cosas que le ofrecía el Estado, el gobierno, las cosas institucionales, pero sí están ahí, con aquellas co- 
sas que sí le interesan, que generalmente no son institucionales, porque no necesariamente la institucionalidad representa a los jóvenes» (Dinamarca, entrevista). Es evidente que la revolución pingüina fue un hecho que demostró al Estado y a la sociedad en general el interés por la educación, por el quehacer público grosso modo.

No se debe olvidar que este estudio se desarrolló con los protagonistas de esa «revolución» 2006-2009 y en donde estos mismos jóvenes fueron capaces de coordinar un movimiento estudiantil nacional, con una lógica y un proyecto común (derogación de la LOCE, entre otras), en donde el sentido democrático fue ejemplar a la sociedad y la clase política, estos estudiantes generaron espacios de diálogo, debate, asambleas soberanas, etcétera.

Muchos de estos estudiantes también son sujetos activos en movimientos sociales, en agrupaciones populares, en comunidades religiosas, en colectivos sociales, etcétera, lo que le da un carácter aún más relevante a lo que planteamos como el quehacer ciudadano.

Actualmente el medioambientalismo es uno de los movimientos sociales más importantes y novedosos a nivel local e internacional, con ejemplos a nivel mundial, y en donde la conciencia ambiental es fundamental en la nueva mentalidad ciudadana. Uno de los objetivos comunes de estos movimientos ambientalistas es poder cambiar la lógica del mercado capitalista y la visión del Estado en temas ambientales. Reafirmando esta misma lógica, en la pregunta acerca de si cuidar el medio ambiente es una forma de identidad ciudadana, el 58,2\% respondió definitivamente que sí, a diferencia del 0,9\% que respondió que no.

Por lo tanto, podemos inferir que los estudiantes poseen una clara conciencia medioambiental, producto de las significativas coyunturas ambientales del último tiempo a nivel internacional, nacional, regional y local. Casos emblemáticos son Celulosa Arauco, Pascua Lama, las hidroeléctricas en La Serena y los conflictos medioambientales con los pescadores artesanales de Coquimbo. Tengamos en cuenta que las instancias políticas no se han encargado de abordar el tema de una manera pertinente; por lo tanto, consideramos que son los jóvenes quienes se han hecho cargo de un problema social y local. Algunos claros matices del significado del ser ciudadano son el quehacer por lo público; vivir en un contexto físico y social que respete y dialogue con la diferencia (como plantea Mauricio Hoyos), en un ambiente con igualdad de oportunidades y posibilidades de acceso a condiciones de vida digna.

A pesar del desprestigio del estilo musical hip-hop, el cual es visto por la mayoría del sector adulto como sinónimo de marginalización, 
drogas y delincuencia, sorprendentemente un $68 \%$ de los jóvenes estudiantes encuestados ven en el hip-hop un claro fomento del desarrollo de la identidad juvenil. El hip-hop es una herramienta de expresión y caracterización de sus anhelos, sueños, programas y proyectos sociales.

Las experiencias por parte del profesorado en establecimientos públicos son de suma relevancia para comprender el fenómeno del hip-hop. Dentro de las instituciones públicas es común ver a los jóvenes estudiantes amotinarse en lugares donde no puedan ser vistos por las autoridades del establecimiento, y así crear espacios de diálogo, reflexión, crítica al sistema actual, a los carabineros, a los políticos, a los profesores, a la iglesia, a la droga, etcétera. Grupos emblemáticos de los jóvenes son Salvaje Decibel, Subverso, Guerrillero Oculto, Newen Kara, entre otros. Las «rimas», como ellos llaman a los cánticos, se escuchan frecuentemente en los recreos, o dentro de las mismas aulas. Experiencias como éstas son recurrentes en establecimientos a lo largo del país. Resulta común escuchar en los jóvenes estudiantes expresiones musicales surgidas del hip-hop, como las que a continuación presentaremos:

\author{
WENA WACHOS \\ He aquí un idealista con ideas listas \\ Y una tarea convertirlas en realidad mismas, \\ Sea como sea la pista capitalista le daré pelea \\ Creando conciencia... \\ Confío a todo corazón de verdad, \\ Que la única solución es la educación popular (poblacional)
}

SALVAJE DECIBEL

El tema de la expresión musical del hip-hop es muy decidora en la construcción de los discursos ciudadanos de los estudiantes. Al analizar los cantos de los grupos de hip-hop más significativos en el tema de la expresión de identidad, se puede concluir que poseen claros lineamientos de las teorías de construcción social ciudadana: tolerancia entre los pares, rechazo y desprestigio a todo lo relacionado con la institucionalidad, adhesión y valoración a lo marginal, a lo indígena, a lo popular y a lo ambiental.

Se puede apreciar que los jóvenes, en los actuales contextos informacionales, poseen más bagaje en lo referente a temas internacionales y de políticas extranjeras, también se puede apreciar que se tiene conocimiento por temas relacionados a los «males sociales», etcétera. Esto simplemente deja entrever que los estudiantes construyen su 
identidad y sus discursos en base a expresiones musicales como el hip-hop, entrelazando esto con temas de contingencia social, política y económica, lo que no deja de ser importante, debido a que este estilo musical nace en las poblaciones marginadas de muchos países de América, generalmente en contextos de pobreza, discriminación y marginalización social.

En este sentido, los jóvenes tienen un alto índice de consumo cultural, y una forma propia de relacionarse en sociedad, los jóvenes asisten a eventos optan por un estilo propio de sociabilidad y ampliar su visión del mundo, buscar un sentido de pertenencia e identidad personal. Los jóvenes no son un grupo homogéneo en el consumo cultural, hay diferentes intereses y motivaciones, una gran diversidad, son quienes gustan de ir a conciertos y obtener música, lo que implica una forma de vestir, relacionarse de acuerdo a sus intereses musicales.

El resultado que a continuación se presentara tiene un significado muy importante, debido al actual estado del arte en lo relacionado al desarrollo de la mala imagen que la sociedad tiene hacia los jóvenes. En este mismo sentido, podemos inferir que producto de esto los jóvenes construyen identidades al margen de la institucionalidad y la sociedad mayor. Volviendo al instrumento de la medición, ¿por qué motivo los jóvenes son discriminados negativamente? el $30,1 \%$ se inclina por la opción, por ser considerados un problema, el 26,2\% por no creer en sus potencialidades, el $22,7 \%$ por ser considerados un peligro, y el 20,5\% por ser vistos como desordenados.

Los jóvenes estudiantes creen que la principal razón de la discriminación es producto de ser considerados un problema y esto no es casualidad, ya que a principios de la década de los 90 los jóvenes comienzan a adquirir un protagonismo relevante en el escenario social, solo que esta vez, ya no como portadores de cambio o esperanzas, sino que bajo el alero de la «leyenda negra». Producto de esto el rol que han tomado el Estado y la sociedad mayor con respecto a los grupos minoritarios. Se trata de no ver a los jóvenes como interlocutores calificados, sino verlos como sujetos de políticas públicas. «En nuestras sociedades la idea de una ciudadanía tutelada por el Estado para el caso de los jóvenes menores, es decir, cuando es el propio Estado el que responde ante la sociedad por estos jóvenes» (Dinamarca, entrevista). Ante este escenario, las juventudes se repliegan hacia espacios marginales, o territoriales poco tradicionales, espacios en los cuales las relaciones sean entre ellos. En este sentido, «el lugar de la juventud, y en especial la que se encuentra en situaciones de pobreza, una 
gran mayoría, está justamente allí, frente a los paradigmas, las incertidumbres y los retos de insertarse o marginarse, de incorporarse o rechazar estas realidades» (Cañas, 2003:5).

En la mayoría de los casos se opta por la opción de automarginación y de reconstrucción de los espacios, «espacios donde tengan sentido y significado, espacios cara a cara, todas estas cosas como las tribus urbanas, son una forma más de expresión» (Dinamarca, entrevista).

Para los estudiantes de La Serena y Coquimbo, las expresiones callejeras sí son formas de expresar la identidad ciudadana. Debemos volver a mencionar que para éstos la ciudadanía es la capacidad de participar en el quehacer público, y no solo ser parte de la formalización del concepto; por lo tanto, podemos inferir que sí poseen una noción de lo que es la ciudadanía y cómo ella radica en la acción y participación social. Esto puede fundamentarse en la pregunta realizada $\dot{c} c r e e s$ que las expresiones artísticas callejeras desarrollan tu identidad ciudadana? Si bien aquí la opción «a veces» se lleva el 34,2\% de las preferencias, la mayoría está repartida en «siempre» con el 26,2\%, y generalmente con el $29,7 \%$. Esto se puede interpretar como un notorio valor que se le entrega a las expresiones artísticas callejeras y la fuerte relación que hay con la identidad ciudadana, demostrando que la formación ciudadana para ellos también radica en el ámbito cultural.

Mayor significancia adquiere también si los colectivos juveniles son una forma de ejercer la ciudadanía. La opción «probablemente sí» posee las preferencias con el $37,9 \%$, seguido por «no estoy seguro» con el 36,3\%, indicando que para la mayoría de los estudiantes el tema de los colectivos juveniles es poco conocido. Aun así, apenas el 5,1\% cree que los colectivos juveniles «definitivamente no» ejercen la ciudadanía. A pesar de un poco conocimiento respecto a que son los colectivos juveniles, estos sí le dan un carácter de relevancia, a diferencia de considerarlo algo negativo en la formación del ciudadano. Por lo tanto, las expresiones callejeras, musicales y artísticas en general, que posean significancia con lo social y lo participativo serán vistas por los jóvenes estudiantes como claros ejercicios del ciudadano.

Ahora nos enfocaremos en cómo los estudiantes «ven el rol del profesor», la asignatura de historia y las instituciones educativas en la construcción del su ser ciudadano.

En lo referente a los profesores en general, podemos aseverar que esta profesión posee una desvalorización social, por lo tanto se genera descrédito por su labor y sus demandas, además de cuestionar su rol 
educativo en la esfera social. Relevante es conocer qué impresión tienen los jóvenes del protagonismo de los docentes en su formación ciudadana a través del instrumento y el posterior análisis.

¿Son los profesores un aporte a tu formación ciudadana? Los estudiantes se inclinan con un 76,1\% a la opción sí y sólo un 22,8\% por la opción NO, lo que deja entrever que el rol del profesorado en términos de formación ciudadana está visto por los alumnos de manera significativa en la formación, dándole un carácter positivo. Por lo tanto, es imprescindible que los docentes estén al tanto de esta categoría que le entrega el alumnado. Pues a pesar del rechazo de las juventudes por todo lo que sea tutelado, autoritario, regularizado, estatizado, político e institucional, etcétera, aun así consideran que la labor del docente es importante en su formación. En esta misma lógica, la pregunta relacionada a si la asignatura de historia es importante a la formación ciudadana con opinión, los estudiantes se inclinaron por considerar definitivamente sí con un 43,5\% de las elecciones de los estudiantes, ratificando el impacto que tienen las clases de historia en las formaciones ciudadanas y sociales. Definitivamente no sólo posee un $5,7 \%$. Lo cual deja entrever que si bien las clases de historia basadas en los planes y programas poseen poca relevancia y lógica con las actuales formas de la identidad ciudadana, aun así los jóvenes las visualizan como un claro referente social.

Resulta necesario dar énfasis en estos dos puntos, el rol del docente y la asignatura de historia, ya que es de suma significancia focalizar ahí el quehacer docente, fomentando y construyendo realidades de cambio y protagonismo con los alumnos, respetando las múltiples visiones y generando nuevos contextos educativos, esta vez centrado, al igual que ellos, en el reconocimiento de las nuevas expresiones sociales, las cuales están en constante construcción pero enfocadas en lo público y lo social.

Además de poder visibilizar las formas de cómo los estudiantes están construyendo nuevas formas de concebir la ciudadanía, en contextos totalmente ajenos a los establecidos por los Estados y la sociedad mayor, en donde éstos reconocen que no solo ejercen el derecho a ciudadano al hacer uso de su derecho a sufragio, o respetando los códigos sociales, sino que también ejercen ciudadanía en espacios no tradicionales, en espacios marginales y con herramientas poco convencionales a las «políticamente establecidas».

La organización poblacional, las expresiones artísticas y culturales, la creación de discursos e interpretaciones sociales y las formas de 
crear instancias de solidaridad y progreso ciudadana son cada vez más complejas y adquieren relevancia en los contextos juveniles, es por eso que la tarea docente, y más aun estatal, es poder reconocer y valorizar lo que están haciendo los jóvenes, para así, tal vez, poder construir un país y una democracia más plena.

\section{CONCLUSIONES}

Sobre los planes y programas del Mineduc, relativos a los temas de ciudadanía y participación, los jóvenes presentan varias impresiones.

En relación con los contenidos de primero medio, las preguntas se orientaron al tema "participación». Es así que frente a la consulta ¿qué significa para ti ser ciudadano?, los estudiantes de cuarto año de enseñanza media respondieron lo siguiente en un orden de mayor a menor de los porcentajes: participación 40,7\%, compromiso 24,4\%, ideales $14,9 \%$, futuro $14,3 \%$ y obligación $5,3 \%$. Considerando este alto porcentaje, los alumnos lo han asociado durante su primer año de enseñanza media, incluso han escuchado esta asociación en los medios de comunicación, particularmente en las franjas electorales y en las elecciones tanto locales y nacionales. No obstante esta comparación, en el marco teórico señala Reguillo que el concepto de ciudadano es más «un conjunto de garantías sociales cuyo sentido es el de ofrecer una plataforma mínima de seguridad que busca equilibrar los desniveles sociales» (Reguillo, 2003:7).

Además, hay que considerar que tanto participación y compromiso son los porcentajes altos que se han dado en esta pregunta, por ende, los estudiantes relacionan la noción de ciudadano con la acción de participar y tener un compromiso frente al orden nacional; recordemos que este concepto se trabajó en primer año de enseñanza media, en la unidad de educación cívica, entregada por los planes y programas de historia y ciencias sociales.

Respecto de la pregunta ¿participas en algún partido político?, los estudiantes respondieron NO en un 92,6\%; mientras el 7,3\% respondió sí y un $0,2 \%$ no supo responder. Esto quiere decir que los alumnos, por una parte, al no ser mayores de edad, no están inscritos (impedimento legal) y, por el otro, que no están interesados en participar en algún partido político. Además cabe señalar que los estudiantes aún están en una etapa de búsqueda de un tipo de identidad, lo cual deben buscar y desarrollar a partir de su discernimiento ideológico, el cual se vincula con el crecimiento intelectual de cada persona en esta etapa de la vida. 
Resulta interesante constatar que el 7,3\% los estudiantes están interesados en participar en los partidos políticos, o al ser mayores de edad, formar parte de algún partido, al cual se sientan identificados con sus posturas ideológicas.

Con lo anterior, se comprueba lo que López indica respecto de otro estudio afín, cuando sostienen que «en una investigación realizada por Rodrigo Gangas en el año 2005 se señala que no se sienten identificados con el sistema político, ya que éste no responde a sus intereses» (López, 2006:11). Está claro que los estudiantes no se sienten identificados con los partidos y sus lógicas de acción y nexo con el medio; incluso el mismo López menciona en esta cita que «el $71 \%$ señala que los partidos sólo se acuerdan de los jóvenes en las campañas electorales» (López, 2006:11).

En relación a la interrogante ¿te han servido en tu formación personal los temas de educación cívica vistos en primero medio?, los estudiantes respondieron a esta pregunta de la siguiente manera: 34,9\% «no estoy seguro», 31,9\% «probablemente sí»; 13,6\% «definitivamente sí»; 10,8\% «definitivamente no» y 8,7\% «probablemente no».

A partir de los resultados obtenidos, es preocupante detectar que los alumnos dudan que los temas de educación cívica tengan alguna influencia o impacto en su formación personal e intelectual. Un total de $34,9 \%$ de los alumnos dudan o no están seguros de haber aplicado los conceptos de esta asignatura entregados en primero medio, o, como indican algunos especialistas, en dicho periodo de estudio los estudiantes no signaron significativamente el proceso educativo, en gran medida por que la «mayoría de edad» se vislumbra muy lejana, cuestión que aminora sus intereses respecto de estos temas y experiencias de vida.

Siguiendo con el orden de porcentajes, el 31,9\% de los estudiantes de cuarto año de enseñanza media «sí» declaran haber empleado los conceptos dados por educación cívica en su vida cotidiana. En este sentido, se debe estipular que si bien es cierto que los planes y programas de enseñanza de media de primer año hacen una introducción a la educación cívica, estos, al transcurrir tres años de formación secundaria no fueron internalizados sostenidamente o definitivamente no fueron parte crucial en la reflexión y experiencia pedagógica de los educandos.

Hagamos un ejercicio. Si tomamos en cuenta los porcentajes por separado la situación de análisis se torna compleja y difusa; pero al unir las alternativas positivas la situación cambia, pues dan un porcen- 
taje alto de adscripción, incluso si se unen las alternativas de negación la panorámica cambia. Las conclusiones son las siguientes: al sumar los porcentajes los alumnos han servido en su formación personal considerando la suma de los porcentajes que lo afirman. No obstante hay que contemplar un reforzamiento en segundo, tercero y cuarto medio, en unidades afines o vinculantes.

Por último, frente a la consulta: ¿qué significa el Estado para ti? los estudiantes del último año de enseñanza media contestaron lo siguiente: 27,1\% «orden»; 25,7\% «desarrollo»; 23,7\% «autoritarismo»; 13,8\% «Protección» y 8,8\% «Represión». Para los estudiantes, el Estado significa «orden», puesto que mantiene controlados todos los ámbitos tanto políticos, económicos como social y cultural. Además ven al Estado como imponente frente a algún inconveniente o dificultad dentro del país que «desordene» los esquemas.

Luego, en relación con la noción de «desarrollo», este término es amplio pues implica las áreas de educación, salud, economía, cultural, promoción social, etcétera. Los estudiantes marcan esta alternativa por que consideran que sí se han logrado avances en estas áreas y que se reflejan en el día a día. Además complementan esta indicación con los medios de comunicación que informan a la sociedad la modernización del país. Un gran ejemplo es el proyecto Bicentenario, en donde se han realizado construcciones en diferentes partes del país una de esas construcciones - como se dijo al comienzo de este trabajo — es el bypass de La Cantera (Coquimbo), el cual facilita la circulación de automóviles y camiones provenientes del Norte Grande y viceversa. No hay que olvidar que como docentes se deben conocer y explicar las funciones que cumple el Estado, desde donde los estudiantes pueden dimensionar el organigrama, misiones y visiones de esta suprainstitución.

Sigamos adelante. ¿Qué valor le asignas a la fiesta del bicentenario? Las autoridades han difundido estos hitos y le han dado la clasificación de importante y simbólica, ya que en el 2010 se cumplen 200 del inicio del proceso de emancipación, por lo cual es pertinente escudriñar la opinión de los estudiantes frente a esta coyuntura histórica, discusión abordada primeramente en la introducción de este trabajo y en el marco teórico.

Frente a la consulta anterior, los estudiantes respondieron lo siguiente: $59,1 \%$ «positiva»; $23 \%$ «ni positiva ni negativa»; 13,1\% «no sabría decir» y 4,6\% «negativa». Los alumnos de colegios tanto municipales como particulares subvencionados de cuarto año respondieron en un 59,1\% que esta celebración o conmemoración es positiva, ya que 
une al país como nación. Por otra parte, los porcentajes de las alternativas neutrales (ni positiva ni negativa y no sabría decir) alcanzando estas respuestas un $36,1 \%$ de las preferencias. Esta cifra es preocupante y decidora a la vez, pues, al no tener los jóvenes claridad sobre qué o por qué se está festejando o conmemorando el Bicentenario, aun constando la gran cantidad de recursos invertidos en publicidad en los diferentes medios de comunicación, sin mediación pedagógica, los estudiantes pierden el sentido de esta conmemoración. La confusión es evidente: reality shows se refieren al tema, grandes series televisivas presentan las historias de héroes nacionales los domingos en horario estelar, pero nadie explica los contextos. Por ende, como profesores de Historia es nuestra labor dar a conocer los motivos y alcances de esta conmemoración a nuestros alumnos, para que estén claros qué estamos celebrando o qué vamos a conmemorar, si es que así lo deciden hacer.

Según Cavieres, «a tres años del Bicentenario, es necesario considerar la historia. La historia profunda del país, la historia real, no en términos negativos ni pesimistas» (Cavieres, 2007:165). Lo que acentúa este autor es considerar lo que realmente se está difundiendo y llamando a conmemorar y no perder el sentido histórico de estos 200 años de vida republicana. En síntesis, su llamado, especialmente para los profesores de historia, es asumir una postura revisionista que no reproduzca «mitos» $\mathrm{y}$ «chauvinismos» heredados por la historiografía tradicional.

Por último, se les preguntó a los estudiantes ¿consideras que la democracia en Chile lucha por la igualdad y justicia entre las personas? Los estudiantes respondieron de la siguiente forma: 29,9\% «probablemente sí»; 25,8\% «no estoy seguro»; 15,4\% «probablemente no»; $14,7 \%$ «definitivamente no» y 13,3\% «definitivamente sí».

Los estudiantes de cuarto año medio han respondido mayoritariamente que "probablemente sí» nuestra democracia lucha por la igualdad y justicia. No obstante, al considerar las alternativas válidas que dan crédito a la pregunta, este porcentaje inicial sube a un 43,2\%. Con esta afirmación, se puede realizar una comparación con la pregunta 52, en la cual uno de los porcentajes más altos fue el «orden», o sea, al relacionarlo se puede esbozar la idea de que el Estado al simbolizar «orden» lleva consigo un deber en la lucha contra la desigualdad y la injusticia que existen en nuestros barrios, poblaciones y ciudades, esperando que algún día terminen las brechas y asimetrías.

Al considerar las alternativas válidas, también hay que tomar en cuenta las inválidas, por cuanto algo «nos quieren decir». Las respuestas negativas — respecto del Estado- consideran el 30,1\%. Esta ma- 
nifestación es alarmante, ya que estos alumnos no ven resultados sino conflictos sin resolver, que eternizan la desigualdad social. Los jóvenes, por medio de los medios de comunicación, poseen claridad respecto de la presencia en nuestro país de grados de desigualdad e injusticia social, en este sentido, marcan negativamente frente a esta interrogante por la preocupación que esto les genera de cara al futuro personal y familiar. Así como «orden» se relaciona con cierta certeza juvenil en relación a la labor del Estado en temas sociales, el rechazo juvenil a esta labor se relaciona con «autoritarismo» y «represión».

Los docentes del subsector de historia y ciencias social, frente a este orden de cosas, deben promover entre sus estudiantes, dentro y fuera del aula de clases, relaciones de igualdad y equidad, signadas por conductas marcadas por la justicia y el bien común.

Continuando con las preguntas, la 63 pretende vislumbrar ciertas posturas valóricas frente al «otro», en este caso, el inmigrante sudamericano ¿respetas a inmigrantes peruanos, bolivianos o ecuatorianos que puedas encontrar en la calle o ver en una esquina?, los estudiantes respondieron categóricamente: sí 79,3\% y no 19,5\%.

Antes de concluir la presentación de este trabajo de investigación indiquemos al menos tres cuestiones de fondo.

En primer lugar, se debe consignar que esta discusión reviste una importancia crucial para el quehacer pedagógico, pues escudriñar en temáticas como las de construcción de identidad en jóvenes estudiantes implica deconstruir las formas de hacer historia entre sujetos diversos, que interactúan en espacios locales, hilvana propuestas de sentido y dan sus opiniones frente a la alteridad. Al rearticular los sistemas comunicativos y las propuestas de sentido, los sujetos activan nuevos esquemas y estructuras que reordenan las imágenes en torno a la institucionalidad estatal, legislativa y societal. ¿Qué tiene que ver esto con el estudio en cuestión? Por medio de la consulta y reflexión a sujetos juveniles, se pueden articular indicaciones que permitan trabajar e intervenir en estos grupos etarios desde indicadores «cercanos» $\mathrm{y}$ «asertivos», que permitan «entender» $\mathrm{y}$ «entenderse» a docentes y estudiantes en contextos educativos.

En segundo lugar, indiquemos que los estudiantes secundarios de La Serena y Coquimbo presentan en sus opiniones y comentarios semejanzas notorias sobre temas como la política, la historia, la ciudadanía y el barrio. En este sentido, resulta apropiado recordar los postulados teóricos sobre los cuales descansa esta tesis, cuando indican que la juventud actual es parte de una larga historia de exclusión y estereo- 
tipos que la han «signado» como un grupo homogéneo, polémico y «destructivo», negando de manera integra la diversidad que los caracteriza y las diferentes vertientes de acción social que esquematizan.

Los estudiantes de La Serena y Coquimbo, de liceos municipalizados y colegios particulares subvencionados, enfatizan en ciertos aspectos y ámbitos de la vida. No presentan líneas argumentales unidireccionales, sino que cruzan opiniones y juicios a partir de los mensajes transmitidos por los medios de comunicación, la publicidad, la música, la familia, los amigos y la escuela. Nada es contradictorio o fuera de foco. Por ejemplo, un observador externo apostaría que entre varias alternativas de «rechazo social» los estudiantes marcarían de manera unánime la que condena el narcotráfico, no obstante dicha tendencia asume un espacio secundario frente a alternativas como violencia contra niños y animales. ¿No reconocen los jóvenes secundarios el flagelo de las drogas como un ítem relevante? Sí lo reconocen, aunque se aproximan al tema de tal manera que priorizan la experiencia inmediata; en dicho sentido, la violencia cotidiana se torna más relevante y significativa que otras alternativas tan válidas como esta.

En tercer lugar, se debe consignar que el hito Bicentenario en Chile debe ser aprovechado por el mundo académico y pedagógico como una oportunidad de debate y reflexión acerca de la institucionalidad nacional, temas en muchas ocasiones tildados de ideologizados como los «dos millones de jóvenes que no se inscriben en los registros electorales», la «crisis del sistema de partidos políticos», el «voto voluntario», la «inscripción automática», la «detención por sospecha» o la «rebaja de la edad para ser imputados en la justicia ordinaria».

LA SERENA (CHILE), AGOSTO 2010

RECIBIDO: AGOSTO 2010 ACEPTADO: OCTUBRE 2010

\section{REFERENCIAS BIBLIOGRÁFICAS}

CAÑAS, JUAN JosÉ (2003): «Ciudadanía juvenil: exclusión-inserción». Última Década N¹9. Viña del Mar: Ediciones CIDPA.

CAVIERES, EDUARDO (2007): «Historia y bicentenario: ¿ilusiones o realidades? La necesidad de considerar la historia». En JosÉ PARENTINI (editor): Historiadores chilenos frente al bicentenario. Santiago: UCSH. 
DinAmarca, PaOla (2009): Entrevista. Psicóloga, académica de la Universidad de La Serena y la Universidad Pedro de Valdivia, La Serena, miércoles 23 de septiembre.

LÓPEZ GONZÁLEZ, JuAN (2006): «Ciudadanía juvenil en el Chile post dictadura. El movimiento secundario del año 2006 y las organizaciones de autoeducación popular». Santiago: OPECH.

PNUD (2002): Transformaciones culturales e identidad juvenil en Chile. Santiago: PNUD.

RECABARREN, LuIS EMILIO (1965): Ricos y pobres a través de un siglo de vida republicana. Santiago: Editorial Recabarren.

Reguillo, Rossana (2003): «Ciudadanías juveniles en América Latina». Última Década N¹9. Viña del Mar: Ediciones CIDPA.

ROZAS, GERMÁN e IVÁN ARREDONDO (compiladores) (2006): Identidad, comunidad y desarrollo. Santiago: Mideplan.

SALAZAR, GABRIEL (2007): «Fiestas centenarias en Chile: ¿ritos del eterno retorno?». En JosÉ PARENTINI (editor): Historiadores chilenos frente al bicentenario. Santiago: UCSH.

Touraine, Alain (1996): «Juventud y democracia en Chile». Revista Iberoamericana de Juventud $\mathrm{N}^{\circ} 1$. Madrid: OIJ. 